\title{
Experimental Study on Reynolds Number Evolution of Gas-Filled Coal
}

\author{
Chao Liu $\mathbb{D}^{1,2}$ Minghui $\mathrm{Li}^{1,2,3}$ and Honggang Zhao $\mathbb{D}^{1,2}$ \\ ${ }^{1}$ State Key Laboratory of Coal Mine Disaster Dynamics and Control, Chongqing University, Chongqing 400030, China \\ ${ }^{2}$ College of Resource and Environmental Sciences, Chongqing University, Chongqing 400030, China \\ ${ }^{3}$ State Key Laboratory of Coal Resources and Safe Mining, China University of Mining and Technology, Xuzhou 221116, China
}

Correspondence should be addressed to Chao Liu; 20142002009@cqu.edu.cn and Honggang Zhao; hg.zhao@cqu.edu.cn

Received 8 January 2019; Accepted 27 May 2019; Published 1 July 2019

Academic Editor: Mohammad Sarmadivaleh

Copyright ( 2019 Chao Liu et al. This is an open access article distributed under the Creative Commons Attribution License, which permits unrestricted use, distribution, and reproduction in any medium, provided the original work is properly cited.

\begin{abstract}
The flow state of gas in coals is very complicated. We should pay attention to whether the permeability calculated by Darcy's law is in accordance with the actual situation. We conducted an experiment on coal permeability and deformation under fixing confining pressure and increasing axial stress conditions. The objective is to investigate the variation of Reynolds number Re. In this study, the dynamic evolution of the Reynolds number is calculated under the relevant assumptions. The Reynolds number increases with an increase in the axial stress. In addition, the larger the value of initial Reynolds numbers, the greater the value of Re in the postpeak, and the possibility of nonlinear flow state is higher. Further, if the mass density $(\rho)$ and fluid viscosity $(\mu)$ are constant, the decrease in the amplitudes of the flow rate is less than the increase in the equivalent diameter of the seepage path. Moreover, the tensile stress generated around the pores and fractures parallel or nearly parallel to the axial stress direction with increase in the axial stress results in an increase in the Reynolds numbers and equivalent diameter of the seepage path increase due to the development, expansion, and penetration of the cracks.
\end{abstract}

\section{Introduction}

In the process of underground mining, in situ stress, gas pressure, and coal deformation are changing constantly. Under the combined effect of various factors, the engineering geological disaster, such as coal and gas outburst, is very prone to occur. The migration characteristic of gas in coals is closely related to the occurrence of gas disasters. However, the dynamics of the Reynolds number reflect the flow state of the gas in coals under different stress arrangement. Accordingly, the Reynolds number is of great significance for preventing gas disaster. Therefore, it is very necessary to study the variation of Reynolds number for gas-bearing coal.

Vidhya et al. [1] concluded that Reynolds number has the effect of increasing axial velocity skin friction, axial velocity, normal velocity skin friction, and heat transfer rate both in the case of impermeable plate and porous plate. Under the condition of increasing confining pressure, Ranjith and Darlington [2] conducted an experimental study on the flow of single-phase water and airflow through a rock joint to evaluate the linear or nonlinear relationship between Reynolds number and pressure change. In addition, the applicability of Forchheimer's relation was tested. Kovscek et al. [3] experimentally studied the flow characteristics of nitrogen, water, and aqueous foam through a transparent replica with a naturally rough-walled rock fracture. The hydraulic aperture of the fracture was about $30 \mu \mathrm{m}$. By analogizing the flow between parallel plates, the authors described the single-phase flow of nitrogen and water. With the Reynolds number close to one, the inertial effects caused by fracture roughness become important in single-phase flow. Mohan et al. [4] calculated the Reynolds number under the hydrodynamic conditions and concluded that the flow of fluid in the reservoir fractures is laminar flow. The hydraulic conductivity of rock joints under normal load without shearing or after shear displacements was tested by Boulon et al. [5]. They built a mesoscale model to describe flow changes. The model is locally based on the cubic law and considers the reduction of roughness. Using this model, they give the maximum Reynolds number of the 


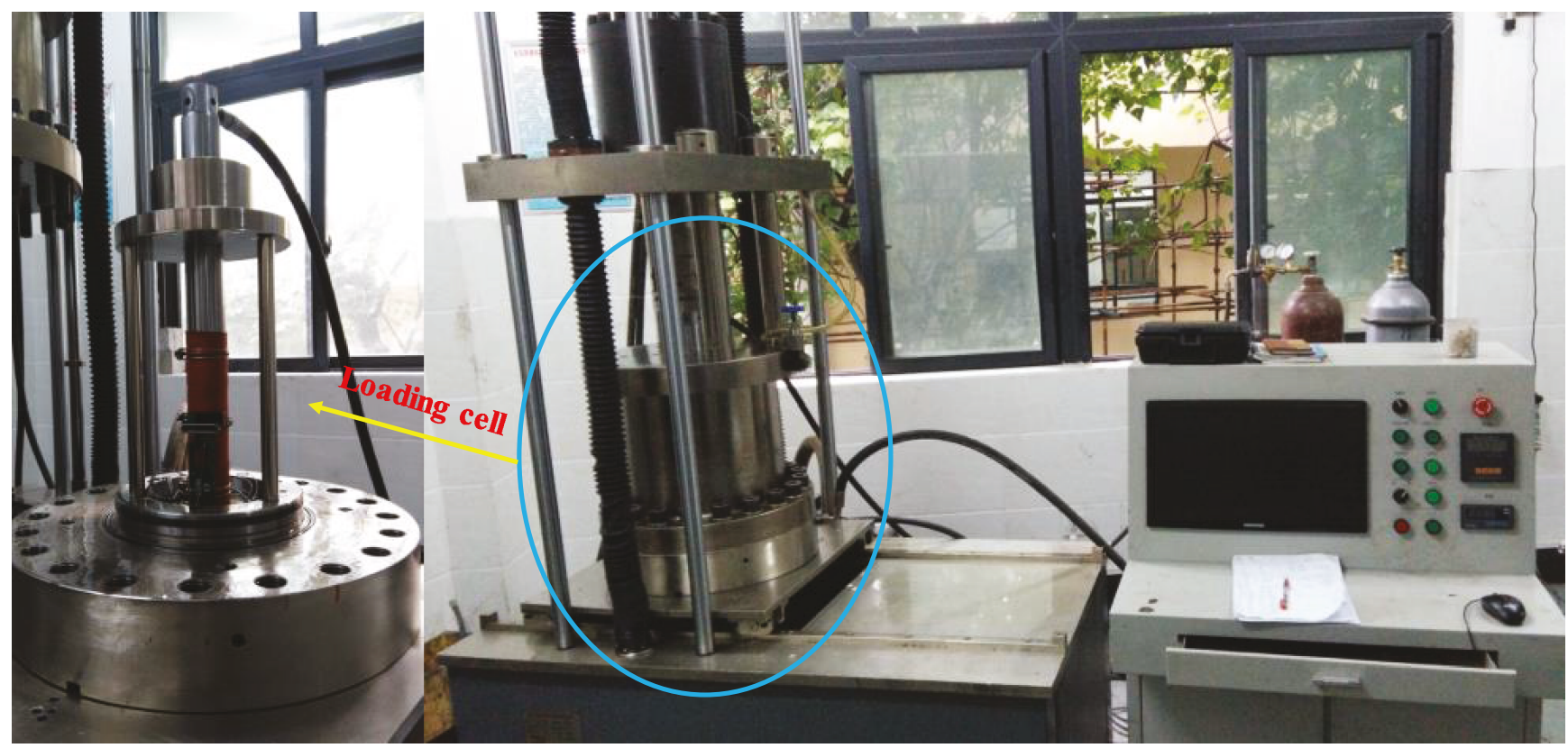

FIgURE 1: Servo-controlled seepage equipment for thermal-hydrological-mechanical coupling of coals and rocks.

flow. App et al. (2002) concluded that the effective relative permeability of the gas for the single-phase cases depends upon three variables, capillary number, Reynolds number, and saturation, which all varied throughout the core. These studies show that the identification of the fluid flow state can independently be done without using Darcy's law. Moreover, Darcy's law is not applicable in any case. However, researchers use Darcy's law to calculate permeability of coals and rocks [6-11], which indicates inconsistency with the practice, and therefore, further study is needed.

In summary, despite the Reynolds number being an important dimensionless parameter for discriminating the flow fluid behavior, the research on the evolution of the Reynolds number in the process of loading axial stress on gas-filled coal is rarely reported. Given that, in order to reveal the gas flow state, it is necessary to study the Reynolds number evolutions by carrying out the gas permeability experiment under triaxial compression conditions. The study also provides a useful reference to select an appropriate model (based on Darcy's law and non-Darcy's law) for the permeability calculation.

\section{Experimental Setup and Scheme}

2.1. Experimental Setup. The experiments were conducted with the newly developed servo-controlled seepage apparatus for thermal-hydrological-mechanical (THM) coupling of gas-infiltrated coals $[12,13]$. The apparatus is composed of the following main components: a servo loading system, a pressure chamber, a gas pressure control system, a data acquisition and storage system, and an auxiliary system. The accuracy of this measurement system is $\pm 1 \%$ for stress, $\pm 1 \%$ for deformation, and $\pm 0.1^{\circ} \mathrm{C}$ for temperature control. The setup can simulate the experimental study of multifield
TABLE 1: In situ stress of the fully mechanized working face 2461.

\begin{tabular}{lccc}
\hline In situ stress & $\begin{array}{c}\text { Magnitude } \\
(\mathrm{MPa})\end{array}$ & $\begin{array}{c}\text { Dip } \\
\text { angle }\left({ }^{\circ}\right)\end{array}$ & $\begin{array}{c}\text { Azimuthal } \\
\text { angle }\left(^{\circ}\right)\end{array}$ \\
\hline Maximum principal stress & 26.6 & -6.7 & 90.1 \\
Intermediate principal stress & 19.4 & -16.8 & 358.1 \\
Minimum principal stress & 8.5 & -71.8 & 201.1 \\
\hline
\end{tabular}

coupling conditions of porous media under different in situ stresses, mining stresses, and fluid pressures.

The experimental setup and loading cell are shown in Figure 1.

2.2. Experimental Specimens. Coals were obtained from the fully mechanized working face 2461 of outburst coal seam $\mathrm{C}_{1}$ in Baijiao Coal Mine of Sichuan Coal Industry Group. Its buried depth is about $582.5 \mathrm{~m}$. The in situ stress in the field is shown in Table 1. The measured average moisture content and density of coal specimens in the same coal seam were $1.866 \%$ and $1.507 \mathrm{~kg} / \mathrm{m}^{3}$, respectively. The uniaxial compressive strength of raw coal is $25.82 \mathrm{MPa}$, the elastic modulus is $2.29 \mathrm{GPa}$, the tensile strength is $2.06 \mathrm{MPa}$, the initial porosity is 0.0538 , and the initial permeability is $0.0193 \times 10^{-3} \mu \mathrm{m}^{-2}$. Poisson's ratios are 0.14 (axial stress is parallel to bedding planes) and 0.22 (axial stress is normal to bedding planes). Coals were drilled, cut, and polished into cylindrical specimens with a height of $100 \mathrm{~mm}$ and a diameter of $50 \mathrm{~mm}$. The two ends of the cylindrical specimen were finally ground to meet the requirements of the ISRM [14] suggested methods for the parallelism of the end faces. The prepared specimens can be seen in Figure 2.

2.3. Experimental Scheme. In the first stage of the experiments, the specimens were placed into the loading cell with 


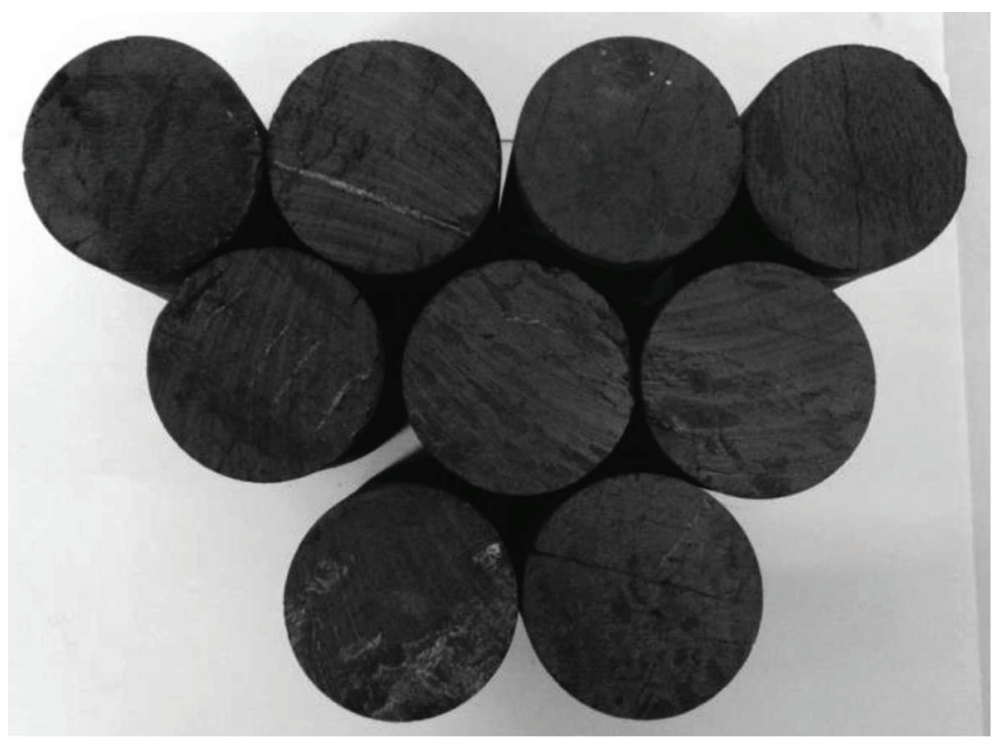

FIGURE 2: Coal samples.

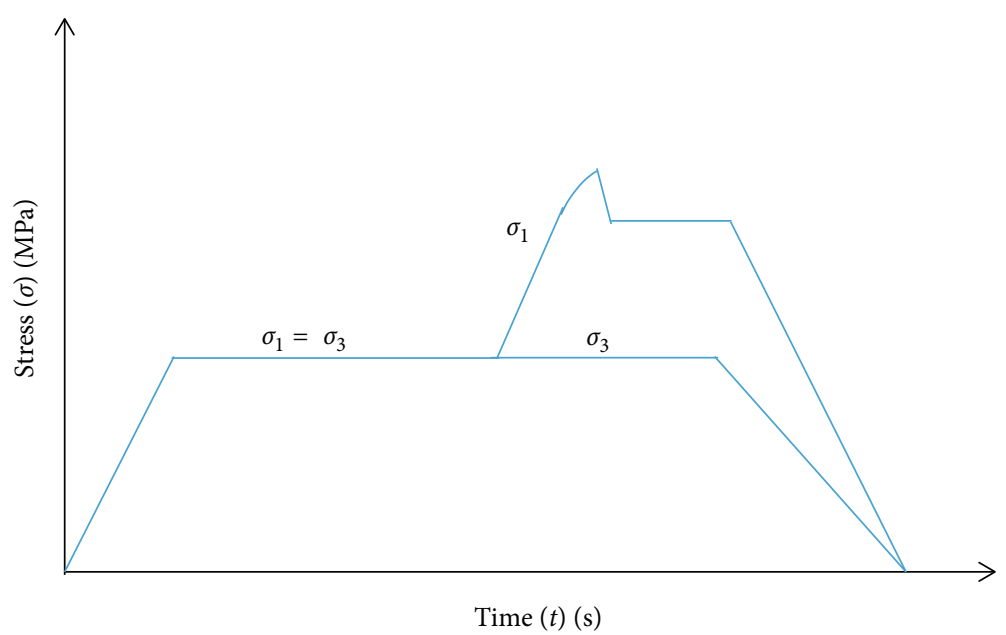

FIGURE 3: The stress path of coal sample loading.

the bedding plane parallel to the axis (Figure 1). Methane $\left(\mathrm{CH}_{4}\right)$ was used to be the injection gas at a pressure of $3 \mathrm{MPa}$ during the whole experiment.

The experiment was performed in the following three steps.

Step 1. Axial stress and confining pressure were simultaneously increased to $20 \mathrm{MPa}$ of hydrostatic pressure at the rate of $0.05 \mathrm{MPa} / \mathrm{s}$. The pressure was maintained for 48 hours to balance the adsorption of coals.

Step 2. By keeping the confining pressure unchanged, the axial pressure is switched from force control to displacement control and the coal specimens were loaded at a rate of $0.01 \mathrm{~mm} / \mathrm{min}$ until the coal specimens are in the residual stress region.

Step 3. End the experiment.
The stress path as obtained from the experiment is shown in Figure 3.

\section{Results and Analysis}

3.1. Reynolds Number Derivation. To characterize the flow behavior of the gas in the above experiment, knowledge of the Reynolds number is important. The Reynolds number Re is a dimensionless parameter that characterizes the fluid flow state as follows $[3,4,15]$ :

$$
\operatorname{Re}=\frac{\rho v r}{\mu},
$$

where Re is the Reynolds number, which is the ratio of the inertial forces to the viscous force, and quantifies the relative importance of these two types of forces for the given flow conditions. In equation (1), $\rho$ is the mass density of the fluid 
in $\mathrm{g} / \mathrm{m}^{3}, v$ is the characteristic velocity in $\mathrm{m} / \mathrm{s}, r$ is the characteristic dimension or equivalent diameter of the seepage path in $\mathrm{m}$, and $\mu$ is the fluid viscosity in $\mathrm{N} \cdot \mathrm{m}^{-2} \cdot \mathrm{s}^{-1}$.

In this study, Reynolds number Re is used to determine whether the seepage follows Darcy's law and its calculation formula is

$$
\operatorname{Re}=5.71 \times 10^{-2} \frac{\rho \sqrt{k}}{\varphi^{1.5} \mu} v
$$

Combining equations (1) and (2), we have the following:

$$
r=5.71 \times 10^{-2} \frac{\sqrt{k}}{\varphi^{1.5}}
$$

where $\varphi$ is the porosity of coal under the current stress state.

Based on the designed stress path, the coal is always in the prepeak state and the flow of $\mathrm{CH}_{4}$ in the coal can be characterized by Darcy's law. The permeability equation is as follows $[12,13,16-18]$ :

$$
k=\frac{2 q \mu L P_{2}}{A\left(P_{1}^{2}-P_{2}^{2}\right)},
$$

where $k$ is the permeability in $\mathrm{m}^{2}, q$ is the exit flow rate of $\mathrm{CH}_{4}$ in $\mathrm{m}^{3} / \mathrm{s}, \mathrm{P}_{2}$ is one standard atmospheric pressure in $\mathrm{MPa}, \mu$ is the kinematic viscosity of $\mathrm{CH}_{4}$ in $\mathrm{MPa} \cdot \mathrm{s}$, at the temperature of the test according to Sutherland's formula, $L$ is the specimen length in $\mathrm{m}, P_{1}$ is the entrance pressure in $\mathrm{MPa}$ of $\mathrm{CH}_{4}$ at the test temperature, and $A$ is the cross-sectional area of the coal specimens in $\mathrm{m}^{2}$.

In an extremely short period, the change in the equivalent diameter of seepage path is

$$
\Delta r=d r=d\left(5.71 \times 10^{-2} \frac{\sqrt{k}}{\varphi^{1.5}}\right)
$$

In particular, "an extremely short period" refers to the adjacent time interval when the data acquisition and storage system records the data (the system records the data once per $0.22 \mathrm{~s}$ ). Compared with the time used for experiment, the period can be considered as instantaneous.

Using equation (5), we have the following:

$$
\Delta r=d r=\left(2.855 \times 10^{-2} \frac{d k}{k}-8.565 \times 10^{-2} \frac{d \varphi}{\varphi}\right) \frac{k^{0.5}}{\varphi^{1.5}}
$$

Therefore, the change rate in the equivalent diameter of seepage path is

$$
\frac{\Delta r}{r}=\frac{d r}{r}=\frac{1}{2} \frac{d k}{k}-\frac{3}{2} \frac{d \varphi}{\varphi}
$$

The experimental time used for maintaining the confining pressure and increasing the axial pressure is shorter than that of the adsorption equilibrium; therefore, the deformation induced by the adsorption and desorption of coal matrix is not considered. Accordingly, the change rate of the porosity is as follows [19]:

$$
\frac{d \varphi}{\varphi}=-\frac{1}{K_{P}}\left(\frac{\sigma_{1}+2 \sigma_{3}}{3}-\beta p\right)+\frac{1}{K}\left(\frac{\sigma_{1}+2 \sigma_{3}}{3}-\alpha p\right),
$$

where $\alpha=1-K / K_{m}, \beta=1-K_{p} / K_{m}$, and $K=E / 3(1-2 v)$. Here, $\alpha$ is the Biot coefficient, $K$ is the bulk modulus of coal in $\mathrm{MPa}, E$ is Young's modulus in $\mathrm{MPa}, v$ is Poisson's ratio, $K_{m}$ is the bulk modulus of coal matrixes/grains in $\mathrm{MPa}$, $K_{p}$ is the bulk modulus of fracture system in coals in $\mathrm{MPa}, p$ is the gas pressure in $\mathrm{MPa}$, and $\beta$ is the effective stress coefficient of fractures in coal.

Combining equations (7) and (8), we have the following:

$$
\frac{d r}{r}=\frac{1}{2} \frac{d k}{k}-\frac{3}{2}\left[-\frac{1}{K_{P}}\left(\frac{\sigma_{1}+2 \sigma_{3}}{3}-\beta p\right)+\frac{1}{K}\left(\frac{\sigma_{1}+2 \sigma_{3}}{3}-\alpha p\right)\right] \text {. }
$$

Herein, the coal matrix is considered as a rigid body, so $\alpha=\beta=1$. Accordingly, equation (9) can be rewritten as

$$
\frac{d r}{r}=\frac{1}{2} \frac{d k}{k}-\frac{3}{2}\left(\frac{1}{K}-\frac{1}{K_{P}}\right)\left(\frac{\sigma_{1}+2 \sigma_{3}}{3}-p\right) .
$$

In the absence of the gas sorption effect, the volumetric variation of the porous media satisfies the Betti-Maxwell reciprocal theorem $[20,21]$ and we have the following:

$$
K_{P}=\frac{\varphi}{\alpha} K=\varphi K
$$

Incorporating equation (11) into equation (9), we obtain

$$
\frac{d r}{r}=\frac{1}{2} \frac{d k}{k}-\frac{3}{2}\left(1-\frac{1}{\varphi}\right) \frac{1}{K}\left(\frac{\sigma_{1}+2 \sigma_{3}}{3}-p\right) .
$$

Raw coal is always subjected to confining pressure in the process of increasing axial pressure, so triaxial compression experiment is very different from the uniaxial compression experiment and the deformation modulus and Poisson's ratio are given as follows:

$$
\begin{aligned}
& B=-\frac{\varepsilon_{3}}{\varepsilon_{1}}, \\
& v=\frac{\left(B \sigma_{1}-\sigma_{3}\right)}{\left[\sigma_{3}(2 B-1)-\sigma_{1}\right]}, \\
& E=\frac{\left(\sigma_{1}-2 v \sigma_{3}\right)}{\varepsilon_{1}},
\end{aligned}
$$

where $\varepsilon_{1}$ and $\varepsilon_{3}$ are the axial and radial strains, respectively, and $\sigma_{1}$ and $\sigma_{3}$ are the major and minor principal stresses in $\mathrm{MPa}$.

The permeability of gas reservoirs is a key performance factor in gas production. Permeability directly affects the gas extraction and shale gas yield. Therefore, it is of 


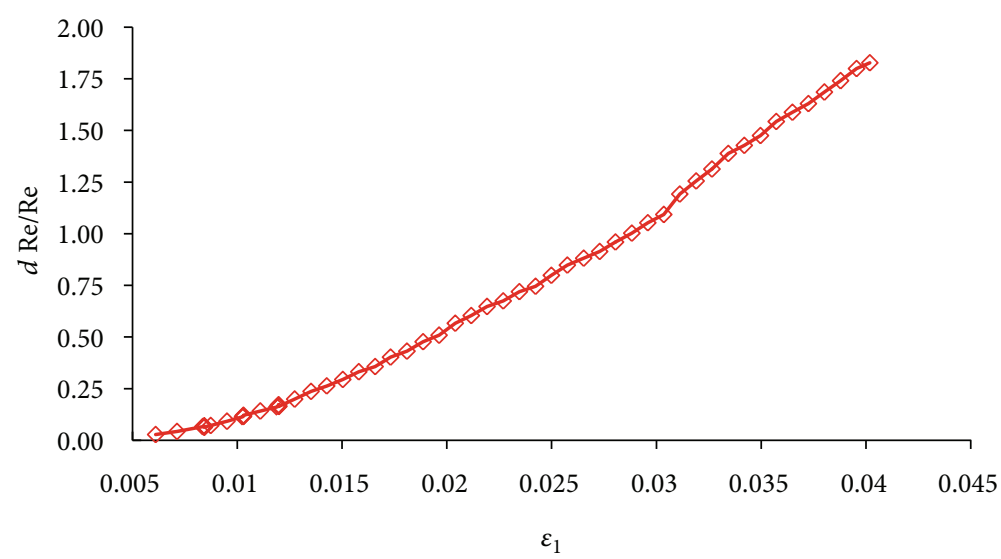

Figure 4: Change of Reynolds number rate $d$ Re/Re with axial strain $\varepsilon_{1}$ in the loading.

paramount interest to study the permeability $[16,22]$. A typical relationship between porosity and permeability is the cubic law and defined as [20, 23-25]

$$
k=k_{0}\left(\frac{\varphi}{\varphi_{0}}\right)^{3}
$$

where $\varphi_{0}$ is the initial porosity of coals, $\varphi$ is the porosity under current state, $k_{0}$ is the initial permeability of coal in $\mathrm{m}^{2}$, and $k$ is the permeability under current state in $\mathrm{m}^{2}$.

Incorporating equation (14) into equation (12), we have the following:

$$
\frac{d r}{r}=\frac{1}{2} \frac{d k}{k}-\frac{3}{2}\left(1-\frac{1}{\varphi_{0}\left(k / k_{0}\right)^{1 / 3}}\right) \frac{1}{K}\left(\frac{\sigma_{1}+2 \sigma_{3}}{3}-p\right) .
$$

In each ultrashort period $\left(\left[t_{i}, t_{i}+1\right]\right)$, the velocity of the flow of gas through coal is considered as constant, that is, $v_{i}=v_{i+1}$. In that case, using equation (1), we have the following:

$\Delta \operatorname{Re}=d \operatorname{Re}=\frac{\rho v_{i+1} r_{i+1}}{\mu}-\frac{\rho v_{i} r_{i}}{\mu}=\frac{\rho}{\mu} v_{i+1}\left(r_{i+1}-r_{i}\right)=\frac{\rho}{\mu} v_{i+1} d r$,

where $v_{i}$ and $v_{i+1}$ are the velocity of flow through coal at $i^{\text {th }}$ and $(i+1)^{\text {th }}$ moments, respectively. $r_{i}$ and $r_{i+1}$ are the corresponding equivalent diameter of the seepage path. It should be noted that $i^{\text {th }}$ moment is an arbitrary time recorded by the data acquisition and storage system during the experiment and $(i+1)^{\text {th }}$ moment is the adjacent time of $i^{\text {th }}$ moment.

Therefore, the change rate of the Reynolds number is

$$
\begin{aligned}
\frac{\Delta \operatorname{Re}}{\operatorname{Re}} & =\frac{d \operatorname{Re}}{\operatorname{Re}}=\frac{d r}{r} \\
& =\frac{1}{2} \frac{d k}{k}-\frac{3}{2}\left(1-\frac{1}{\varphi_{0}\left(k / k_{0}\right)^{1 / 3}}\right) \frac{1}{K}\left(\frac{\sigma_{1}+2 \sigma_{3}}{3}-p\right) .
\end{aligned}
$$

Equation (17) indicates that the change rate of Reynolds number is related to the stress field and permeability. The change rate of Reynolds number ( $d \mathrm{Re} / \mathrm{Re}$ ) versus axial strain $\varepsilon_{1}$ in the loading is shown in Figure 4. We can observe that $(d \mathrm{Re} / \mathrm{Re})$ increases with the increase in the axial strain $\varepsilon_{1}$. Moreover, fitting $d \operatorname{Re} / \operatorname{Re}$ and $\varepsilon_{1}$ in polynomial form is as follows:

$$
\frac{d \operatorname{Re}}{\operatorname{Re}}=830.53 \varepsilon_{1}^{2}+16.537 \varepsilon_{1}-0.1363
$$

The correlation coefficient is $R^{2}=0.9835$.

Accordingly, we assume a quadratic polynomial relationship between the change rate of Reynolds number $(d \mathrm{Re} / \mathrm{Re})$ and axial strain $\varepsilon_{1}$ :

$$
\frac{d \operatorname{Re}}{\operatorname{Re}}=\mathrm{a}_{1}^{2}+b \varepsilon_{1}+c
$$

where $a, b$, and $c$ are the fitting coefficients.

From equation (19), we have the following:

$$
\Delta \ln (\mathrm{Re})=d \ln (\mathrm{Re})=\frac{d \mathrm{Re}}{\operatorname{Re}}=\mathrm{a}_{1}^{2}+b \varepsilon_{1}+c
$$

For the experimental data, $a, b$, and $c$ in equation (19) are $830.53,16.537$, and -0.1363 , respectively. Further, we have the following:

$$
\begin{aligned}
\Delta \ln (\mathrm{Re}) & =\ln \left(\operatorname{Re}_{i+1}\right)-\ln \left(\mathrm{Re}_{i}\right) \\
& =\left(a \varepsilon_{1-i+1}^{2}+b \varepsilon_{1-i+1}+c\right)-\left(a \varepsilon_{1-i}{ }^{2}+b \varepsilon_{1-i}+c\right) \\
& =\Delta \varepsilon_{1}\left[a\left(\varepsilon_{1-i+1}+\varepsilon_{1-i}\right)+b\right],
\end{aligned}
$$

$\ln \left(\frac{\operatorname{Re}_{i+1}}{\operatorname{Re}_{i}}\right)=\Delta \varepsilon_{1}\left[a\left(\varepsilon_{1-i+1}+\varepsilon_{1-i}\right)+b\right]$. 


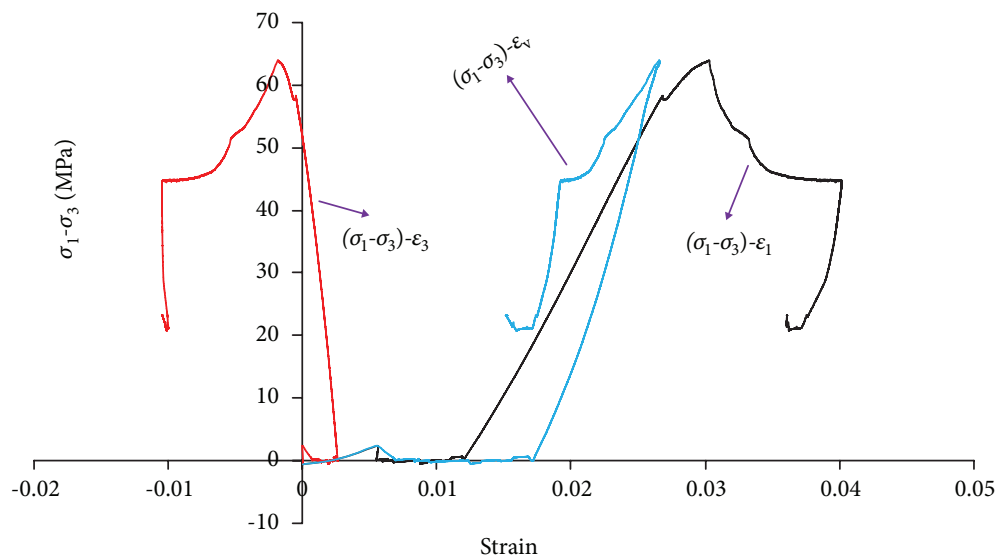

Figure 5: Relationship between deviatoric stress $\left(\sigma_{1}-\sigma_{3}\right)$ and strain $\varepsilon$ in the process of loading.

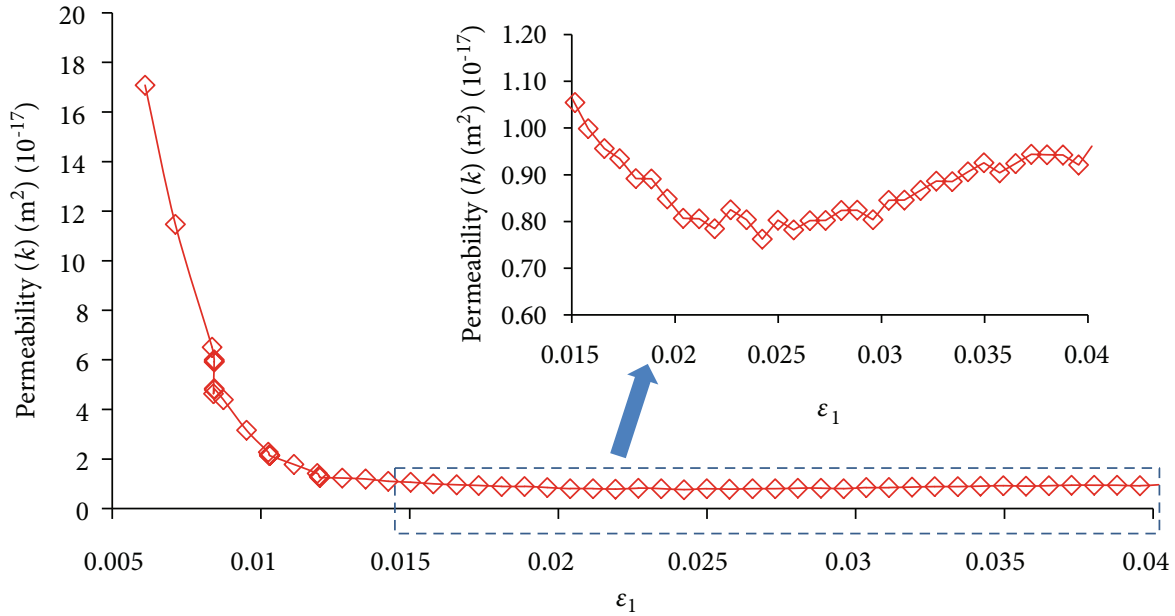

FIgURE 6: Change of permeability $k$ with axial strain $\varepsilon_{1}$ in the process of loading.

Taking logarithm on both the sides of equation (22), we obtain the ratio of Reynolds number at the adjacent times:

$$
\frac{\mathrm{Re}_{i+1}}{\operatorname{Re}_{i}}=e^{\Delta \varepsilon_{1}\left[a\left(\varepsilon_{1-i+1}+\varepsilon_{1-i}\right)+b\right]},
$$

where $\operatorname{Re}_{i}$ and $\mathrm{Re}_{i+1}$ are the Reynolds number at the $i^{\text {th }}$ and $(i+1)^{\text {th }}$ moments, respectively. $\varepsilon_{1-1}$ and $\varepsilon_{1-i+1}$ are the corresponding axial strains, respectively. Here, $\Delta \varepsilon_{1}=$ $\left(\varepsilon_{1-i+1}\right)-\left(\varepsilon_{1-1}\right)$.

On combining equation (23) with the experiment, we get

$$
\frac{\operatorname{Re}_{i+1}}{\operatorname{Re}_{i}}=e^{\Delta \varepsilon_{1}\left[830.53\left(\varepsilon_{1-i+1}+\varepsilon_{1-i}\right)+16.537\right]}
$$

It can be seen from equation (24) that if the Reynolds number $\mathrm{Re}_{0}$ at the initial loading time is known, the Reynolds number for the later stages can be calculated; hence, the flow behavior of gas can also be determined. Additionally, it can provide a reference for the selection of model for the postpeak permeability calculation.
3.2. Variation of Reynolds Numbers during Loading. Figure 5 shows the deviatoric stress $\left(\sigma_{1}-\sigma_{3}\right)$ versus strain $\varepsilon$ (axial strain $\varepsilon_{1}$, lateral strain $\varepsilon_{3}$, and volumetric strain $\varepsilon_{\mathrm{V}}$ ) in the process of loading, and Figure 6 shows the permeability $k$ versus axial strain $\varepsilon_{1}$. The raw coal undergoes the pore and fracture compaction stage, elastic deformation stage, plastic development stage, and residual stress stage (Figures 5 and 6). Accordingly, the permeability changes in a V-type are expected. Because the coal is in a high confining pressure state, there is no sudden increase in the permeability when the axial stress reaches peak stress (Figure 6).

Figure 7 shows the Reynolds number ratio $\left(\operatorname{Re}_{i+1} / \operatorname{Re}_{i}\right)$ versus axial strain $\varepsilon_{1}$ in the process of loading. The range of $\mathrm{Re}_{i+1} / \mathrm{Re}_{i}$ is $[0.999,1.0015]$. Because the range of the region $\Omega \in[1,10015]$ is larger than $\Omega \in[0.999,1]$, so the Reynolds number is $\operatorname{Re}_{i+1}>\operatorname{Re}_{i}$. Therefore, we conclude that the Reynolds number increases with the increase of axial strain $\varepsilon_{1}$.

It is observed that the gas flow state is a linear laminar flow if $\operatorname{Re}<10$ (conforms to Darcy's law) [26, 27], while $10 \leq \operatorname{Re} \leq 100$ indicates a nonlinear laminar flow regime. Hence, a critical Reynolds number 10 determines the 


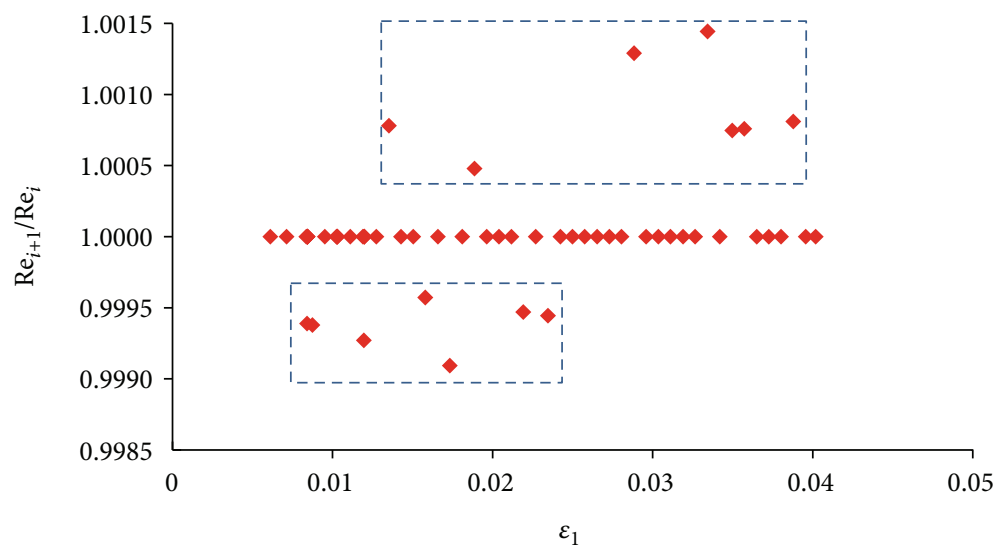

FIGURE 7: Change of Reynolds number ratio $\operatorname{Re}_{i+1} / \operatorname{Re}_{i}$ with axial strain $\varepsilon_{1}$ in the process of loading.

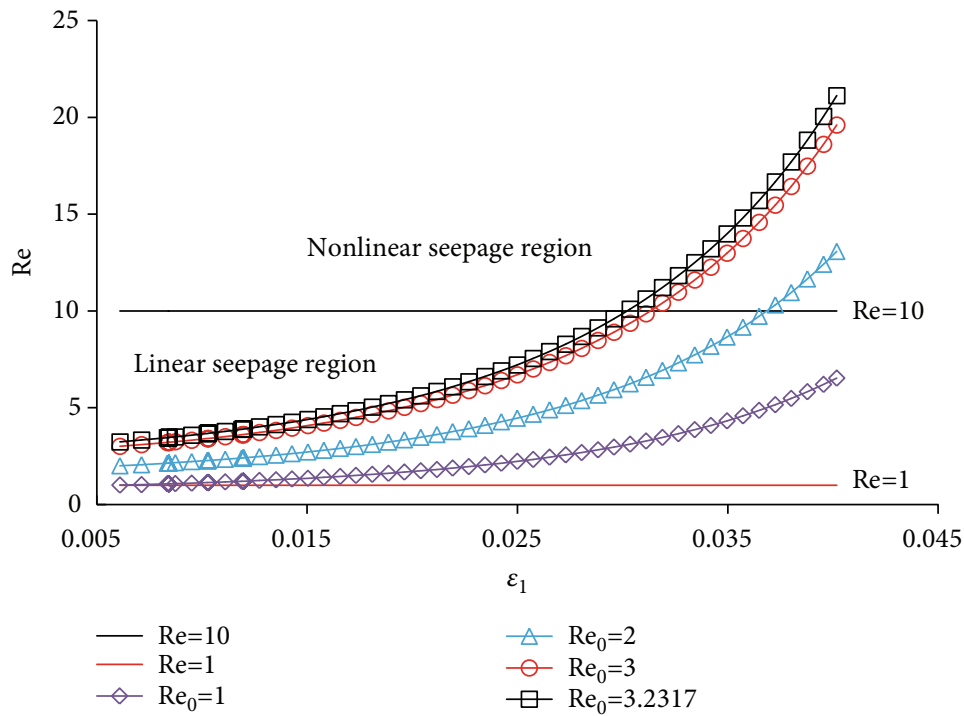

(a)

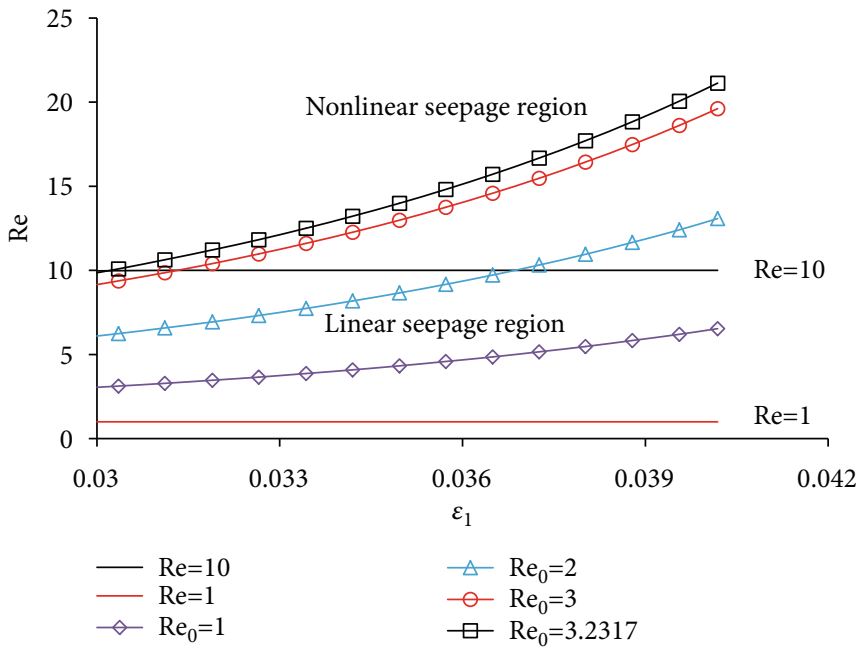

(b)

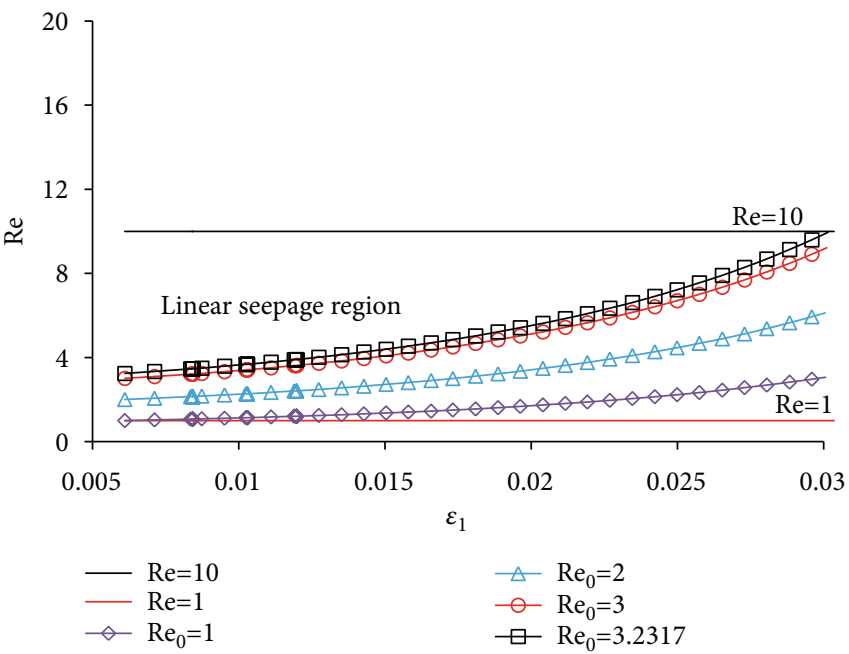

(c)

FIGURE 8: (a) Change of Reynolds number Re with axial strain $\varepsilon_{1}$. (b) Change of Reynolds number Re with axial strain $\varepsilon_{1}$ in the postpeak state. (c) Change of Reynolds number Re with axial strain $\varepsilon_{1}$ in the prepeak state. 
transition from linearity to nonlinearity [28]. Calculations show that, if the gas has a laminar flow before the peak stress, the initial Reynolds number satisfies $1 \leq \mathrm{Re}_{0} \leq 3.2317$ (Figure 8). Further, different initial Reynolds number $\left(\mathrm{Re}_{0}\right)$ could result in Re greater than or less than 10 in the postpeak stage. In the case of higher Reynolds number, the inertial term in Forchheimer flow equations is more significant, and the flux $(Q)$ cannot be accurately predicted by Darcy's law [2, 29-31]. Therefore, the permeability of gas-bearing coal cannot be calculated by using equation (4) in the postpeak stage. In conclusion, a careful selection of the permeability calculation model is necessary.

Essentially, the difference in $\mathrm{Re}_{0}$ is related to the physical characteristics of raw coal and the stress state. Coal body contains abundant pores and fractures with unique roughness, tortuosity [30], boundary conditions, number [32], and distribution of seepage channels. Besides, the in situ stress, gas pressure, and temperature of coals are significantly different $[33,34]$. The internal structure of raw coal is significantly different from that of sandstone and shale. The raw coal contains not only bedding planes but also unique cleat system (face cleat and butt cleat). Moreover, the roughness of fracture surface and the tortuosity of fracture path are difficult to describe quantitatively, which makes the structure of raw coal extremely complex. The influences of face cleat, butt cleat, and bedding plane on permeability are indeed of significant importance. However, the calculation principle of permeability is closely related to the gas flow state, and the Reynolds number determines the gas state. A larger $\mathrm{Re}_{0}$ results in a larger $\mathrm{Re}$ in the postpeak and the higher the probability that the gas is in a nonlinear flow state in the postpeak stage. Based on the capillary model, it is shown that the capillary aperture inside coal can expand under tensile stress on the crack surface, as shown in Figure 9.

At $(i+1)^{\text {th }}$ moment, the Reynolds number can also be given as follows:

$$
\operatorname{Re}^{\prime}=\frac{\rho(v+\Delta v)(r+\Delta r)}{\mu},
$$

where $(\operatorname{Re})^{\prime}$ is the Reynolds number at $(i+1)^{\text {th }}$ moment, $\Delta v$ is the change in the characteristic velocity in an extremely short period, and $\Delta r$ is the change in the equivalent diameter of the seepage path in an extremely short period.

By subtracting equation (1) from equation (25), we have the following:

$$
\begin{aligned}
& \Delta \operatorname{Re}=\frac{\rho}{\mu}[(v+\Delta v)(r+\Delta r)-v r], \\
& \Delta \operatorname{Re}=\frac{\rho}{\mu}(v \cdot \Delta r+r \cdot \Delta v+\Delta r \cdot \Delta v), \\
& \Delta \operatorname{Re}=\operatorname{Re}\left(\frac{\Delta r}{r}+\frac{\Delta v}{v}+\frac{\Delta r \Delta v}{v r}\right) .
\end{aligned}
$$

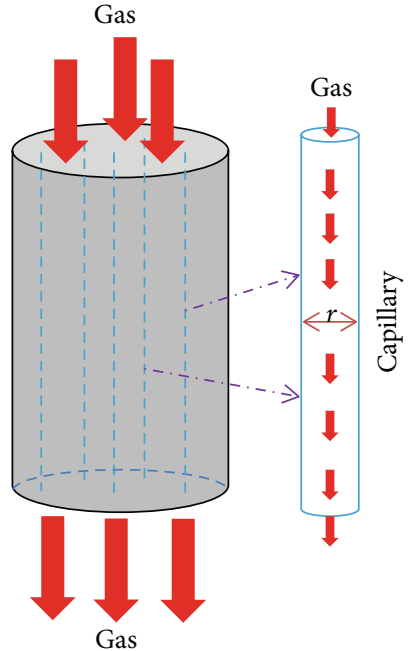

FIgure 9: Capillary model of gas flow in coal sample.

Neglecting the higher order term $((\Delta v \Delta r) /(v r))$ in equation (28) results in

$$
\Delta \operatorname{Re}=\operatorname{Re}\left(\frac{\Delta r}{r}+\frac{\Delta v}{v}\right) .
$$

Herein, we use volume flow $Q$ to characterize characteristic velocity $v$. Accordingly, we have the following:

$$
\Delta \operatorname{Re}=\operatorname{Re}\left(\frac{\Delta r}{r}+\frac{\Delta Q}{Q}\right),
$$

where $\Delta Q$ is the change in the volume flow $Q$ in an extremely short period in $\mathrm{m}^{3} / \mathrm{s}$ and $\Delta \operatorname{Re}$ is the change in the Reynolds number Re in an extremely short period.

$(\Delta Q / Q)$ versus $\varepsilon_{1}$ is shown in Figure 10. Upon comparing Figures 4 and 10, we observe that $|\Delta Q / Q|<|\Delta r / r|$. Under the condition of constant $\rho$ and $\mu$, the decrease in the amplitudes of the flow rate is less than the increase in the equivalent diameter of the seepage path $((\Delta r / r)+(\Delta Q / Q)>0)$, that is, the Reynolds number is increasing continuously $(\Delta \operatorname{Re}>0)$. The change in the equivalent diameter of pores and fractures parallel or nearly parallel to the direction of the maximum principal stress (axial stress direction $\sigma_{1}$ ) is the main factor causing the change of the gas flow state [35]. Moreover, the equivalent diameter is also affected by the axial stress. With increasing axial stress, tensile stress is generated around the above-mentioned pores and fractures. Consequently, the equivalent diameter increases due to the cracks expand and extend along the $\sigma_{1}$ direction. When coals enter the plastic stage, the development, expansion, and penetration of the pores and fractures accelerate the increase in the equivalent diameter, which is manifested by the increasing Reynolds number.

\section{Conclusions}

We performed an experiment on coal permeability and deformation under fixed confining pressure and increasing 


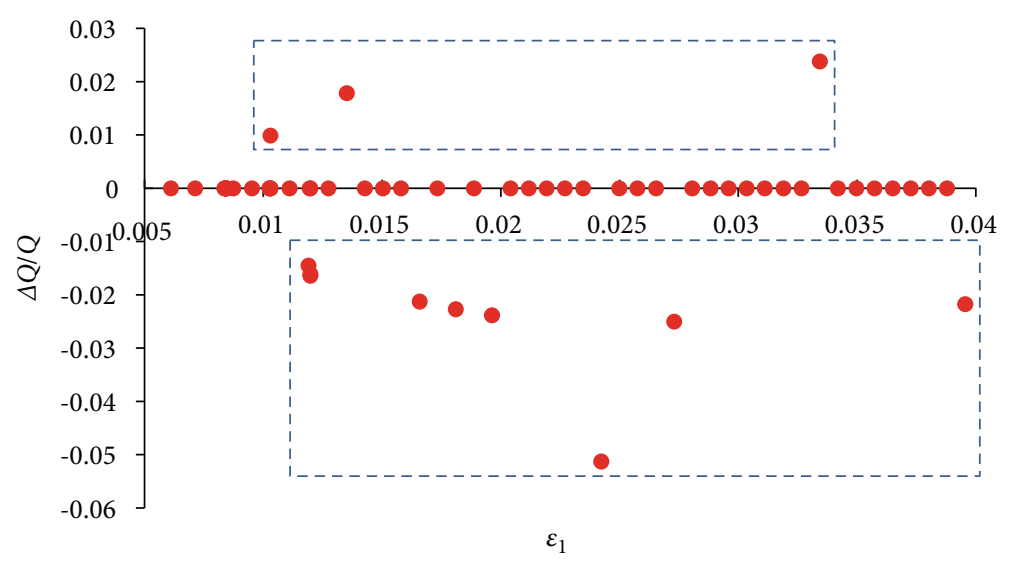

Figure 10: Change of flow rate $\Delta Q / Q$ with axial strain $\varepsilon_{1}$ in the process of loading.

axial stress conditions with the aim to select the permeability model by investigating the variation of Reynolds number. The primary conclusions are as follows:

(i) The dynamic evolution of Reynolds number under the assumption that the coal matrix is rigid and the flow rate is constant in an extremely short period is examined. We find that the Reynolds number increases with an increase in the axial strain

(ii) Different initial Reynolds numbers result in the Reynolds numbers being may be greater than or less than 10 in the postpeak stage. In this case, the permeability of gas-bearing coal cannot be calculated by Darcy's law. Therefore, a careful selection of the permeability calculation model is necessary

(iii) If $\rho$ and $\mu$ are constant, the decrease in the amplitudes of flow rate is less than the increase in the equivalent diameter of the seepage path. Furthermore, the tensile stress generated around the pores and fractures parallel or nearly parallel to the axial stress direction with increasing axial stress results in an increase in the equivalent diameter due to the development, expansion, and penetration of the cracks

\section{Data Availability}

Data available within the article or its supplementary materials.

\section{Conflicts of Interest}

We declare we have no competing interests.

\section{Acknowledgments}

This study was financially supported by the National Natural Science Foundation of China (51434003, 51874053, and 51804049), the China Postdoctoral Science Foundation Funded Project (2017M612917), the Chongqing Postdoctoral Research Project Special Funding (XM2017043), and the Research Fund of State Key Laboratory for Geomechanics and Deep Underground Engineering, CUMT (SKLGDUEK1809).

\section{References}

[1] M. Vidhya, S. Kesavan, and A. Govindarajan, "Injection effects on a vertical channel embedded in porous medium with transpiration cooling and heat source," CiiT International Journal of Artificial Intelligent and Machine Learning, vol. 3, no. 4, pp. 247-252, 2011.

[2] P. G. Ranjith and W. Darlington, "Nonlinear single-phase flow in real rock joints," Water Resources Research, vol. 43, no. 9, 2007.

[3] A. R. Kovscek, D. C. Tretheway, P. Persoff, and C. J. Radke, "Foam flow through a transparent rough-walled rock fracture," Journal of Petroleum Science and Engineering, vol. 13, no. 2, pp. 75-86, 1995.

[4] A. R. Mohan, U. Turaga, V. Subbaraman, V. Shembekar, D. Elsworth, and S. V. Pisupati, "Modeling the $\mathrm{CO}_{2}$-based enhanced geothermal system (EGS) paired with integrated gasification combined cycle (IGCC) for symbiotic integration of carbon dioxide sequestration with geothermal heat utilization," International Journal of Greenhouse Gas Control, vol. 32, pp. 197-212, 2015.

[5] M. J. Boulon, A. P. S. Selvadurai, H. Benjelloun, and B. Feuga, "Influence of rock joint degradation on hydraulic conductivity," International Journal of Rock Mechanics and Mining Sciences \& Geomechanics Abstracts, vol. 30, no. 7, pp. 13111317, 1993.

[6] Z. Pan, Y. Ma, L. D. Connell, D. I. Down, and M. Camilleri, "Measuring anisotropic permeability using a cubic shale sample in a triaxial cell," Journal of Natural Gas Science and Engineering, vol. 26, pp. 336-344, 2015.

[7] Y. Peng, J. Liu, M. Wei, Z. Pan, and L. D. Connell, "Why coal permeability changes under free swellings: new insights," International Journal of Coal Geology, vol. 133, pp. 3546, 2014.

[8] S. Ghabezloo, J. Sulem, S. Guédon, and F. Martineau, "Effective stress law for the permeability of a limestone," International Journal of Rock Mechanics and Mining Sciences, vol. 46, no. 2, pp. 297-306, 2009.

[9] J. Q. Shi and S. Durucan, "Drawdown induced changes in permeability of coalbeds: a new interpretation of the reservoir 
response to primary recovery," Transport in Porous Media, vol. 56, no. 1, pp. 1-16, 2004.

[10] I. Palmer and J. Mansoori, "How permeability depends on stress and pore pressure in coalbeds: a new model," $S P E$ Reservoir Evaluation \& Engineering, vol. 1, no. 6, pp. 539544, 1998.

[11] E. P. Robertson and R. L. Christiansen, "A permeability model for coal and other fractured, sorptive-elastic media," SPE Journal, vol. 13, no. 3, pp. 314-324, 2013.

[12] G. Yin, M. Li, J. G. Wang, J. Xu, and W. Li, "Mechanical behavior and permeability evolution of gas infiltrated coals during protective layer mining," International Journal of Rock Mechanics and Mining Sciences, vol. 80, pp. 292-301, 2015.

[13] W. Li, D. Zhang, and M. Li, "Failure criteria of gas-infiltrated sandy shale based on the effective stress principle," Energies, vol. 9, no. 11, p. 972, 2016.

[14] ISRM, "The complete ISRM suggested methods for rock characterization, testing and monitoring: 1974-2006," in Prepared by the Commission on Testing Methods, R. Ulusay and J. A. Hudson, Eds., pp. 47-48, ISRM, Ankara, Turkey, 2007.

[15] M. A. V. D. Hoef, R. Beetstra, and J. A. M. Kuipers, "LatticeBoltzmann simulations of low-Reynolds-number flow past mono- and bidisperse arrays of spheres: results for the permeability and drag force," Journal of Fluid Mechanics, vol. 528, pp. 233-254, 2005.

[16] M. Li, G. Yin, J. Xu, J. Cao, and Z. Song, "Permeability evolution of shale under anisotropic true triaxial stress conditions," International Journal of Coal Geology, vol. 165, pp. 142-148, 2016.

[17] A. Ghanizadeh, A. Amann-Hildenbrand, M. Gasparik, Y. Gensterblum, B. M. Krooss, and R. Littke, "Experimental study of fluid transport processes in the matrix system of the European organic-rich shales: II. Posidonia Shale (Lower Toarcian, northern Germany)," International Journal of Coal Geology, vol. 123, pp. 20-33, 2014.

[18] M. S. A. Perera, P. G. Ranjith, S. K. Choi, and D. Airey, "The effects of sub-critical and super-critical carbon dioxide adsorption-induced coal matrix swelling on the permeability of naturally fractured black coal," Energy, vol. 36, no. 11, pp. 6442-6450, 2011.

[19] P. Guo, Y. Cheng, K. Jin, W. Li, Q. Tu, and H. Liu, "Impact of effective stress and matrix deformation on the coal fracture permeability," Transport in Porous Media, vol. 103, no. 1, pp. 99-115, 2014.

[20] J. Liu, Z. Chen, D. Elsworth, H. Qu, and D. Chen, "Interactions of multiple processes during CBM extraction: a critical review," International Journal of Coal Geology, vol. 87, no. 3-4, pp. 175-189, 2011.

[21] R. J. S. Brown and J. Korringa, "On the dependence of the elastic properties of a porous rock on the compressibility of the pore fluid," Geophysics, vol. 40, no. 4, pp. 608-616, 1975.

[22] Y. Meng, Z. Li, and F. Lai, "Experimental study on porosity and permeability of anthracite coal under different stresses," Journal of Petroleum Science and Engineering, vol. 133, pp. 810-817, 2015.

[23] G. Cui, J. Liu, M. Wei, X. Feng, and D. Elsworth, "Evolution of permeability during the process of shale gas extraction," Journal of Natural Gas Science and Engineering, vol. 49, pp. 94-109, 2018.

[24] H. Pape, C. Clauser, and J. Iffland, "Variation of permeability with porosity in sandstone diagenesis interpreted with a fractal pore space model," Pure and Applied Geophysics, vol. 157, no. 4, pp. 603-619, 2000.

[25] G. Wang, K. Wang, S. Wang, D. Elsworth, and Y. Jiang, “An improved permeability evolution model and its application in fractured sorbing media," Journal of Natural Gas Science and Engineering, vol. 56, pp. 222-232, 2018.

[26] W. B. Durham and B. P. Bonner, "Self-propping and fluid flow in slightly offset joints at high effective pressures," Journal of Geophysical Research: Solid Earth, vol. 99, no. B5, pp. 93919399, 1994.

[27] A. P. Oron and B. Berkowitz, "Flow in rock fractures: the local cubic law assumption reexamined," Water Resources Research, vol. 34, no. 11, pp. 2811-2825, 1998.

[28] R. W. Zimmerman and I. W. Yeo, "Fluid flow in rock fractures: from the Navier-Stokes equations to the cubic law," in Dynamics of Fluids in Fractured Rock, B. Faybishenko, P. A. Witherspoon, and S. M. Benson, Eds., vol. 122 of Geophysical Monograph Series, pp. 213-224, American Geophysical Union, Washington, DC, USA, 2000.

[29] F. Jiang and T. Tsuji, "Changes in pore geometry and relative permeability caused by carbonate precipitation in porous media," Physical Review E, vol. 90, no. 5, 2014.

[30] Z. Zhao, B. Li, and Y. Jiang, "Effects of fracture surface roughness on macroscopic fluid flow and solute transport in fracture networks," Rock Mechanics and Rock Engineering, vol. 47, no. 6, pp. 2279-2286, 2013.

[31] I. W. Yeo, M. H. De Freitas, and R. W. Zimmerman, "Effect of shear displacement on the aperture and permeability of a rock fracture," International Journal of Rock Mechanics and Mining Sciences, vol. 35, no. 8, pp. 1051-1070, 1998.

[32] J. F. App and K. K. Mohanty, "Gas and condensate relative permeability at near-critical conditions: capillary and Reynolds number dependence," Journal of Petroleum Science and Engineering, vol. 36, no. 1-2, pp. 111-126, 2002.

[33] S. Chen, D. Tang, S. Tao et al., "In-situ stress measurements and stress distribution characteristics of coal reservoirs in major coalfields in China: implication for coalbed methane (CBM) development," International Journal of Coal Geology, vol. 182, pp. 66-84, 2017.

[34] S. Tao, Z. Pan, S. Tang, and S. Chen, "Current status and geological conditions for the applicability of CBM drilling technologies in China: a review," International Journal of Coal Geology, vol. 202, pp. 95-108, 2019.

[35] Y. Cheng and L. N. Y. Wong, "Microscopic characterization of tensile and shear fracturing in progressive failure in marble," Journal of Geophysical Research: Solid Earth, vol. 123, no. 1, pp. 204-225, 2018. 

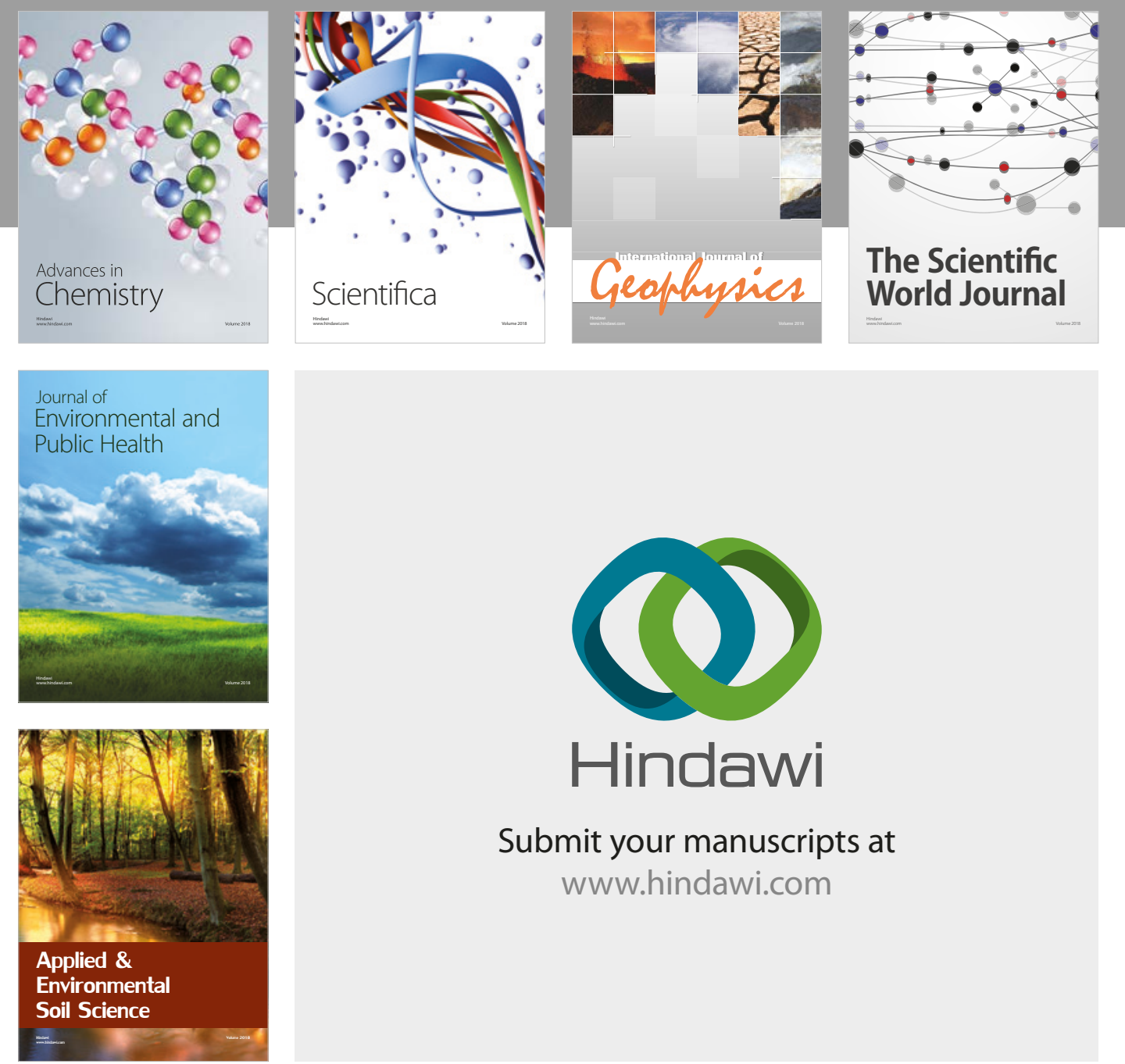

The Scientific

\section{World Journal}
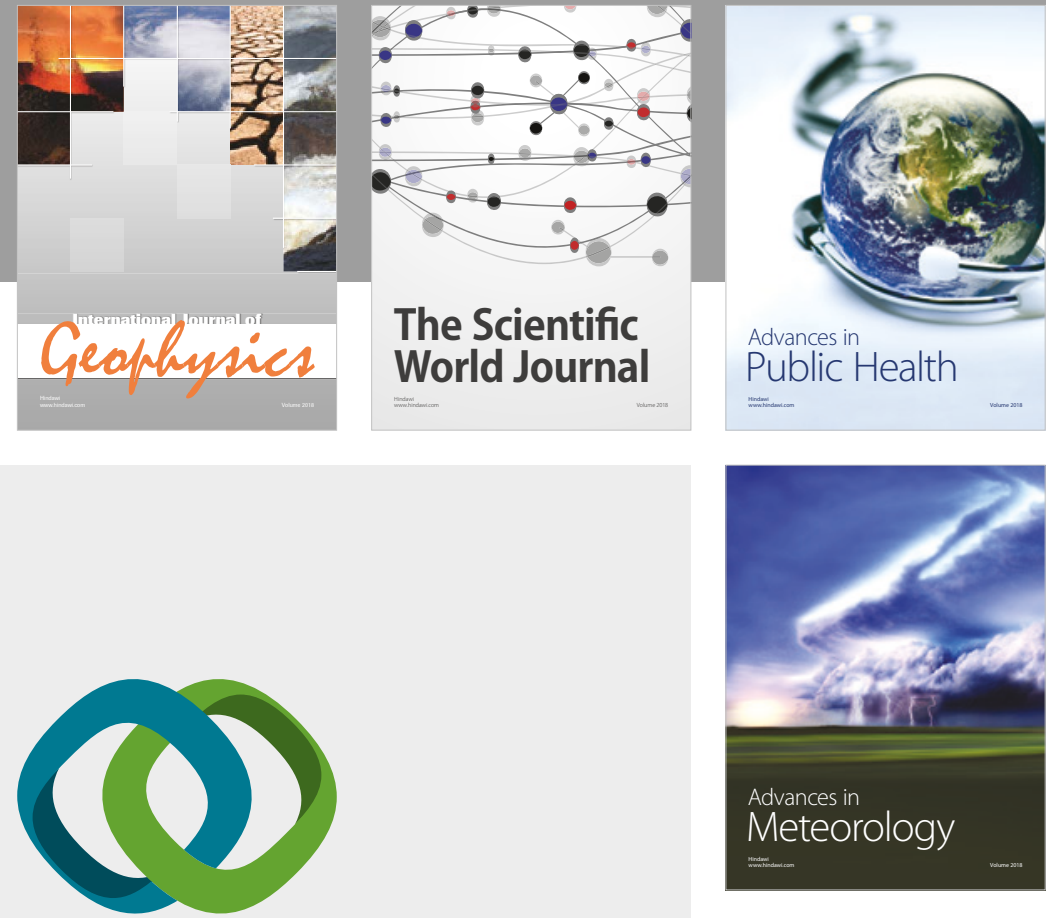

Advan

Public Health

\section{Hindawi}

Submit your manuscripts at

www.hindawi.com
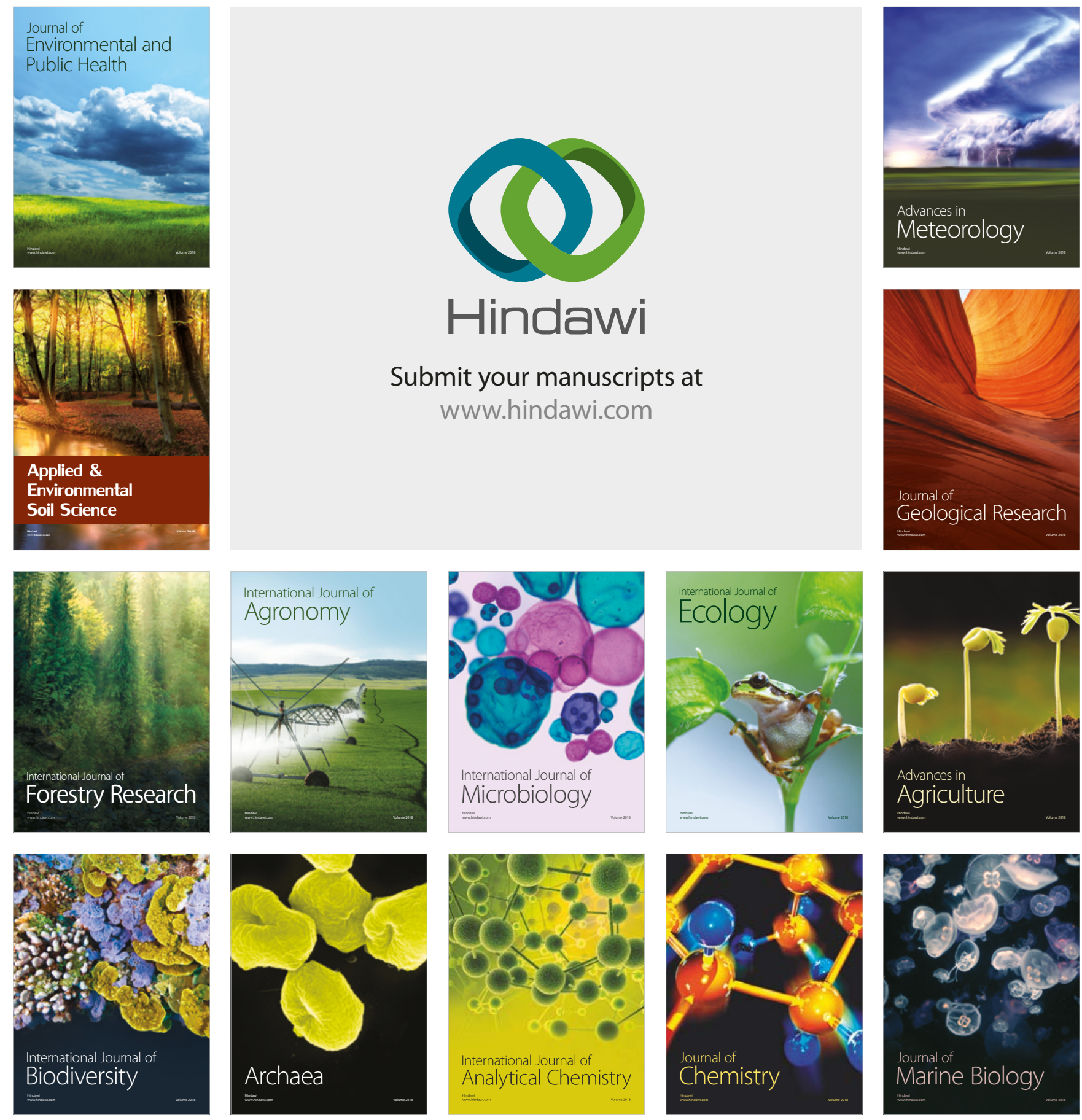